\title{
A Review on the Use of Agriculture Waste Material as Lightweight Aggregate for Reinforced Concrete Structural Members
}

\author{
Kim Hung Mo, ${ }^{1,2}$ U. Johnson Alengaram, ${ }^{1,2}$ and Mohd Zamin Jumaat ${ }^{1,2}$ \\ ${ }^{1}$ Department of Civil Engineering, Faculty of Engineering, University of Malaya, 50603 Kuala Lumpur, Malaysia \\ ${ }^{2}$ Centre of Innovative Construction Technology (CICT), Department of Civil Engineering, University of Malaya, \\ 50603 Kuala Lumpur, Malaysia
}

Correspondence should be addressed to Kim Hung Mo; khmo890815@gmail.com and U. Johnson Alengaram; ujohnrose@yahoo.com

Received 3 August 2014; Accepted 30 November 2014; Published 22 December 2014

Academic Editor: Bin Li

Copyright (C) 2014 Kim Hung Mo et al. This is an open access article distributed under the Creative Commons Attribution License, which permits unrestricted use, distribution, and reproduction in any medium, provided the original work is properly cited.

\begin{abstract}
The agriculture industry is one of the main industries in the Southeast Asia region due to its favourable conditions for plantations. In fact, Southeast Asia region is the world's largest producer of palm oil and coconut. Nevertheless, vast plantation of these agriculture products leads to equally large amount of waste materials emanating from these industries. Previously, researchers have attempted to utilize the resulting waste materials such as oil palm shell, palm oil clinker, and coconut shell from these industries as lightweight aggregate to produce structural grade lightweight aggregate concrete. In order to promote the concept of using such concrete for actual structural applications, this paper reviews the use of such agriculture-based lightweight aggregate concrete in reinforced concrete structural members such as beam and slab, which were carried out by researchers in the past. The behaviour of the structural members under flexural, shear, and torsional load was also summarized. It is hoped that the knowledge attained from the paper will provide design engineers with better idea and proper application of design criteria for structural members using such agriculture waste as lightweight aggregate.
\end{abstract}

\section{Introduction}

Many countries in Southeast Asia region rely on the agriculture industry for their economic wellbeing. This is because most parts of this region have a tropical humid climate and receive abundant rainfall throughout the year, which are suitable for growing crops. Besides that, the presence of highly fertile soils in the region facilitates the production of a rich variety of crops. One of the most prominent agriculture industries in Southeast Asia region is the palm oil industry. Countries in the region, especially Malaysia, Indonesia, and Thailand, have vast oil palm plantations. In fact, these countries contributed to a total of close to $90 \%$ of the world's palm oil production in the year 2009. Due to the diverse use of palm oil, there is a huge demand for palm oil around the world. Nevertheless, the increasing amount of palm oil extraction also leads to the large amount of waste materials produced such as oil palm shell (OPS) and palm oil clinker (POC). OPS is attained directly by breaking the palm kernel shell [1] which occurs as a byproduct from the palm oil extraction process and is usually dumped in the vicinity of the factories which could lead to land pollution. POC, on the other hand, is obtained through the incineration of palm oil waste in the palm oil mills. Subsequently, the POC was discarded as waste material and this could also lead to deterioration of the surrounding. Besides the palm oil industry, the coconut industry is also a major agriculture field in Southeast Asia countries such as the Philippines and Indonesia. Similar to OPS, coconut shell (CS) is also a waste material produced from the coconut industry. CS is usually discarded as waste after the coconut is scraped out [2]. Therefore, it also causes environmental concerns due to its dumping on-site.

Due to the environmental concerns posed by these waste materials, researchers came up with the idea of reusing these wastes as lightweight aggregate (LWA) to produce lightweight 


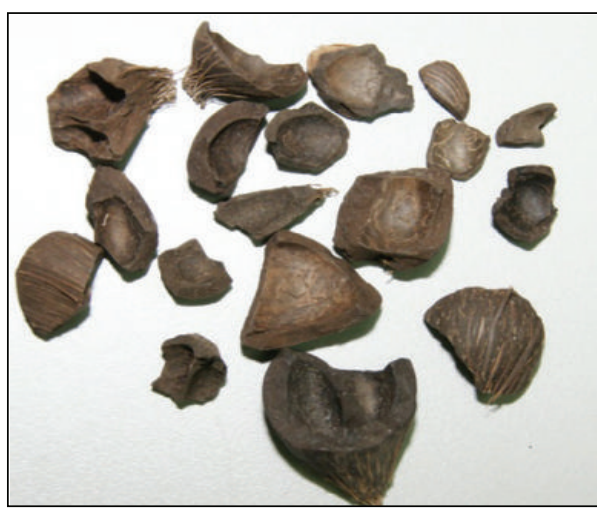

(a)

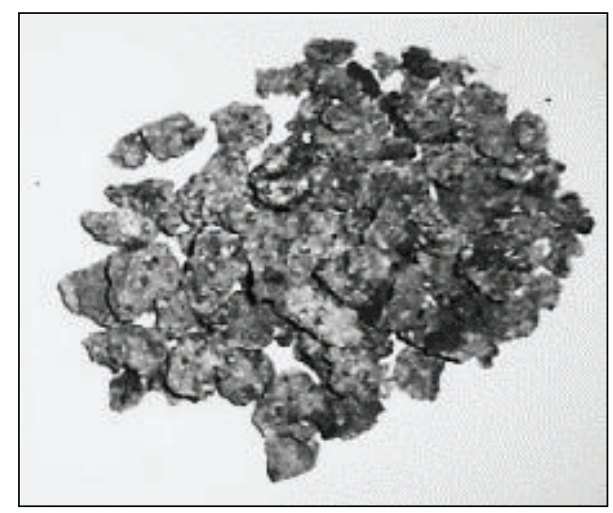

(b)

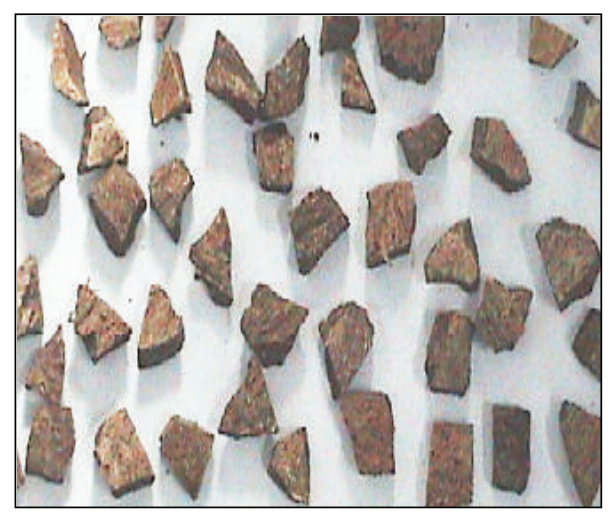

(c)

FIGURE 1: (a) Oil palm shell [10], (b) palm oil clinker [14], and (c) coconut shell [15] as lightweight aggregates.

concrete. In fact, studies on using OPS as LWA for concrete have been carried out for the past 20 years. Research in the early years dealt with the strength development of OSPC [3] and recently high strength lightweight OPS concrete with compressive strength exceeding $40 \mathrm{MPa}$ was successfully developed [4]. Researchers then began to investigate the usability of OPS concrete for structural purposes, as works regarding the flexural behavior of reinforced OPS concrete beams [5-7] as well as that for reinforced OPS concrete slabs [8] were carried out. The shear performance of reinforced OPS concrete beams was also explored by Jumaat et al. [9] and Alengaram et al. [10]. More recently, structural grade POC and CS concrete were also produced and further research on the flexural and shear behaviour of reinforced concrete beams made using $[11,12]$ and CS $[2,13]$ was also carried out. Figure 1 shows the OPS, POC, and CS which were used as LWA.

In order to establish the structural feasibility and provide a general idea on the performance of such reinforced lightweight concrete member, this paper summarizes the findings obtained in past researches with regard to the structural behaviour of reinforced OPS, POC, and CS concrete members. Ideally, it is hoped that the information provided in this review will generate interest amongst researchers and practicing engineers into further developing such reinforced lightweight concrete members for future applications in the construction industry.

\section{Agriculture Solid Waste as Lightweight Aggregate}

\subsection{Oil Palm Shell (OPS)}

2.1.1. Reinforced Concrete Beam. One of the earliest researches regarding the use of OPS in reinforced concrete was carried out by Teo et al. [16] to study the flexural behaviour of the reinforced concrete beam under static loading. In this research, three different tension reinforcement ratios (singly reinforced) were used, namely, $0.46 \%, 0.66 \%$, and $0.98 \%$. It was reported that the beams failed in typical flexural failure mode with steel yielding followed by concrete cover crushing. This suggested that no anomalies were observed despite the use of OPS in the reinforced concrete beam. Interestingly, the experimental ultimate moments were found to be 19$35 \%$ higher compared to the predicted moment using BS 8110 . This was also observed by Teo et al. [17] in a separate study involving the flexural behaviour of singly reinforced OPS concrete beams. Hence, the authors concluded that BS 8110 could be used to give conservative estimate of the moment for reinforced OPS concrete beams. Apart from that, despite the low modulus of elasticity of OPS concrete, Teo et al. [16] found that the reinforced OPS concrete beam gave acceptable serviceability deflection as the span-deflection ratio ranged between 252 and 263 which fell within the limit stipulated in BS 8110 . 


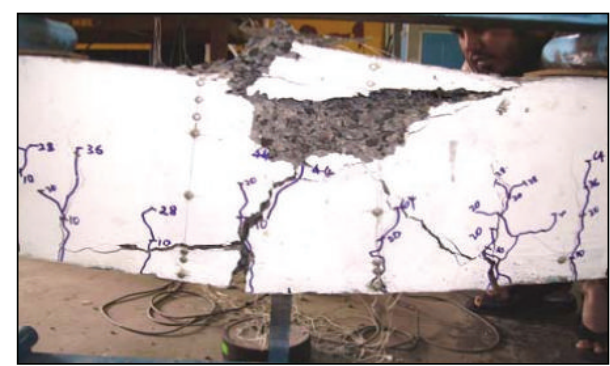

(a)

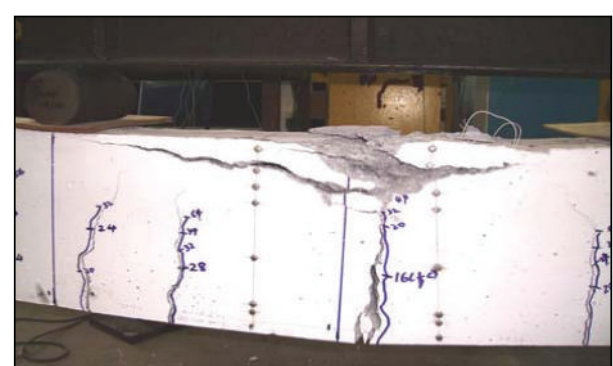

(b)

FIGURE 2: Failure of reinforced (a) OPS concrete and (b) NWC beam [6].

In a more detailed investigation, Teo et al. [5] investigated the flexural behaviour of OPS concrete beams which were singly and doubly reinforced. The tension reinforcement ratio used was in the range of $0.46 \%$ to $3.39 \%$. All the beams were found to exhibit typical underreinforced failure despite the increment in the tension reinforcement of up to $3.39 \%$. The difference between the experimental and predicted moments was observed to be between 4 and $35 \%$ and therefore it was once again suggested that BS 8110 may be used as the design basis since it gave conservative prediction of the ultimate moment. A difference in the range of 4$21 \%$ was observed between the experimental and predicted serviceability midspan deflections based on BS 8110 . It was recommended that, for the doubly reinforced OPS concrete beams, larger beam depths should be used to satisfy the spandeflection ratio as prescribed in BS 8110. When comparing the reinforced OPS concrete beams, the authors observed reduced ductility with the increase in reinforcement ratio. Nevertheless, good ductility was found for the reinforced OPS concrete beams with up to $2.01 \%$ reinforcement ratio since the ductility ratio exceeded 3 . The good ductility behaviour of OPS concrete beams was attributed to the toughness and good shock absorbance provided by the OPS aggregates. Such observation indicates the usefulness of OPS concrete for structural applications since larger deflections could be observed prior to the failure of concrete members and could serve as a warning sign for civilians to escape in case of potential structural member collapse or for early remediation and repairing works to be carried out. In the same investigation, emphasis was also given for the cracking behaviour of the reinforced OPS concrete beams since the cracking behaviour is one of the most important criteria of the serviceability of reinforced concrete members. The crack widths of reinforced OPS concrete beams up to service loads did not exceed the maximum limit of $0.41 \mathrm{~mm}$ stipulated in ACI 318 while the authors also found that design codes such as ACI 318 and BS 8110 both gave reasonable prediction of the serviceability crack widths. This study is of significant importance since it demonstrated that conventional design codes could be safely used in the design for reinforced OPS concrete beams.

In order to further justify that the flexural performance of reinforced OPS concrete beam was on par with conventional reinforced concrete beam and could be used for structural purposes, Alengaram et al. [6] carried out experimental work to compare the flexural behaviour of both types of reinforced concrete beams with equal tension reinforcement ratio and concrete compressive strength. The authors observed brittle failure for conventional reinforced normal weight concrete (NWC) beams whereas the reinforced OPS concrete beams exhibited prolonged deflection and hence failed in a ductile manner. However, the failure zone in the concrete compression region was larger for the reinforced OPS concrete beams (Figure 2). Both ACI and BS codes were found to give close serviceability deflections for the reinforced OPS concrete and NWC beams, which was in agreement with the previous finding by Teo et al. [5]. It should be noted that, despite the relatively low modulus of elasticity of OPS concrete, the serviceability deflections for both types of beams were close. Nevertheless, at failure, it was observed that the reinforced OPS concrete beams exhibited twice the deflection compared to that for NWC beams. The enhanced ductility of reinforced LWC beam made using lightweight scoria aggregates was also observed by Charif et al. [18]. When analysing the crack behaviour of the reinforced concrete beams, the authors reported that the crack widths of the reinforced OPS concrete beams were smaller compared to that for reinforced NWC beams. Besides that, the reinforced OPS concrete beams had more vertical flexural cracks and smaller crack spacings compared to the reinforced NWC beams, which suggest better bond between the OPS concrete and steel reinforcing bars. Based on all the observations in the study by Alengaram et al. [6], it could be seen that, overall, the reinforced OPS concrete beam showed good flexural behaviour and was comparable to conventional reinforced NWC beam. Thus, the use of OPS concrete for structural application could be justified.

Ahmed and Sobuz [7] investigated the static flexural behaviour of reinforced concrete beams made with the combination of varying amounts of OPS and granite. The combination used includes OPS to granite ratio of $1: 1$, $1.5: 8.5$, and $1: 9$. Results showed that the estimations of the first cracking load and ultimate moment capacity using transformed section analysis were close to those observed experimentally. Besides that, the reinforced beams were subjected to long term loading for two cases: uncracked and cracked section. For the beam with OPS to granite ratio of $1: 1$, it was observed that the long term deflection for the cracked 
section of the beam was about $12 \%$ higher compared to that for the uncracked beam and this was attributed to the creep and shrinkage effect. The equation for the long term deflection suggested in ACI Committee 435-R95 underestimated the experimental deflection for this beam. Nevertheless, when considering the beams with lower amount of OPS, the predicted long term deflection using the equation gave better match to the experimental results. Based on this research, it was felt that there is a need for a more detailed research regarding the long term deflection behaviour of reinforced concrete beam containing OPS since the creep and shrinkage effect of OPS concrete could be significantly higher compared to conventional NWC which could cause prediction equation to underestimate the long term behaviour of reinforced OPS concrete beam. The authors also suggested that works on refined tension stiffening model for OPS concrete should be carried out so that the accuracy of prediction equation could be improved.

The study of the shear behaviour of reinforced foamed OPS concrete beams was initiated by Jumaat et al. [9]. When shear links were not included, the reinforced foamed OPS concrete beams showed shear failure mode as demonstrated with the appearances of diagonal cracks whereas the beams exhibited flexural failure mode in the presence of shear links. The authors found that the reinforced foamed OPS concrete beams had about $10 \%$ higher shear strength compared to conventional reinforced NWC beams and attributed this to the good aggregate interlock of OPS aggregates. The shear capacity of the reinforced foamed OPS concrete beams could be well predicted using ACI equations compared to BS equations. Besides that, the deflections of the reinforced foamed OPS concrete beams were generally higher compared to that for the reinforced NWC beams and finite element analysis was found to give close match to the experimental deflection values for the reinforced foamed OPS concrete beams. Similar to the earlier investigation by Alengaram et al. [6] for flexural behaviour of reinforced OPS concrete beams, the average crack spacing for reinforced foamed OPS concrete beams was smaller compared to that of reinforced NWC beams, which suggested better bonding between the OPS concrete and tension reinforcement.

Alengaram et al. [10] further researched the shear behaviour and compared the performance between reinforced OPS concrete and NWC beams with similar concrete compressive strength grade. It was found that the reinforced OPS concrete beams could be achieved up to $49 \%$ higher shear strength compared to conventional reinforced NWC beams. They attributed this to the enhanced dowel action of the reinforced OPS concrete beams in addition to the good aggregate interlock. In this research, the BS and EC codes were found to give good comparison of the shear resistance of reinforced OPS concrete beams, particularly the beams without shear reinforcement. However, in general, the use of numerical analysis gave the closest prediction with an average of $20 \%$ difference compared to the experimental finding. The reinforced OPS concrete beams were found to exhibit larger deflection than the corresponding reinforced NWC beams while the beam without shear reinforcement generally had higher deflection than that for beam with shear reinforcement. This was also reported by Ahmad et al. [19] for reinforced LWC made from expanded slate aggregates. Nevertheless, the deflection of all the reinforced beams at service loads, including that of reinforced OPS concrete beams, conforms to the allowable limit in BS 8110 of $9.6 \mathrm{~mm}$. Therefore, from the investigation of the shear behaviour of reinforced OPS concrete beam carried out by Jumaat et al. [9] and Alengaram et al. [10], it was concluded that the use of OPS concrete is satisfactory for beams subjected to shear loading and even outperformed that of conventional NWC.

2.1.2. Reinforced Concrete Slab. A novel approach in using geogrid to reinforce OPS concrete slab was done by Muda et al. [8]. Geogrid is a high-modulus polymer material made of relatively netlike materials with openings and mainly used as reinforcement. In this study, Muda et al. [8] carried out static flexural tests on the geogrid reinforced OPS concrete slabs. In terms of the ultimate strength, the authors found that increasing the number of layers of geogrid reinforcement led to about $57 \%$ increment in the flexural strength while increasing the amount of OPS led to the reduction in the flexural strength of the geogrid reinforced slabs. This was attributed to the weak properties of OPS caused by its high porosity. The failure mode observed was due to the breakdown in bond of the OPS and cement paste. Nevertheless, the authors concluded that the geogrid reinforced OPS concrete slabs were suitable for the use in construction for residential purposes since the flexural capacity of the slabs fulfilled the ultimate limit state condition specified in BS 8110 for residential floor slab. Besides that, the serviceability deflection of the OPS concrete slab was also within the maximum limit for residential floor as stipulated in BS 8110 . Based on the experimental results, these research works clearly demonstrated that OPS concrete could be safely used for construction of slabs as it adhered to the requirements in design code and this could provide an interesting alternative to conventional reinforced concrete slab since significant dead load could be reduced, particularly for a structural member such as slab which usually covers a large area.

2.1.3. Actual Structural Application. In the year 2001, as shown in Figure 3(a), Universiti Malaysia Sabah constructed a footbridge measuring $2 \mathrm{~m}$ using OPS concrete while, in 2003, a low cost house with floor area of $59 \mathrm{~m}^{2}$, shown in Figure 3(b), was also built using OPS concrete for monitoring purposes.

\subsection{Palm Oil Clinker (POC)}

2.2.1. Reinforced Concrete Beam. In the research involving reinforced POC beam subjected to flexural loading, Mohammed et al. [11] investigated the effect of varying tension reinforcement ratios of the reinforced POC beams, ranging from $0.35 \%$ to $2.23 \%$. All the reinforced POC beams exhibited typical flexural failure, which suggested the use of POC did not bring upon detrimental effect on the flexural behaviour of reinforced concrete beam. The authors also found that the experimental value of the moment capacity of 


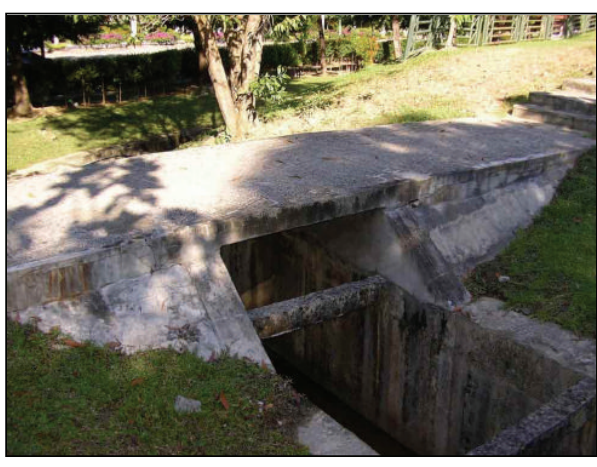

(a)

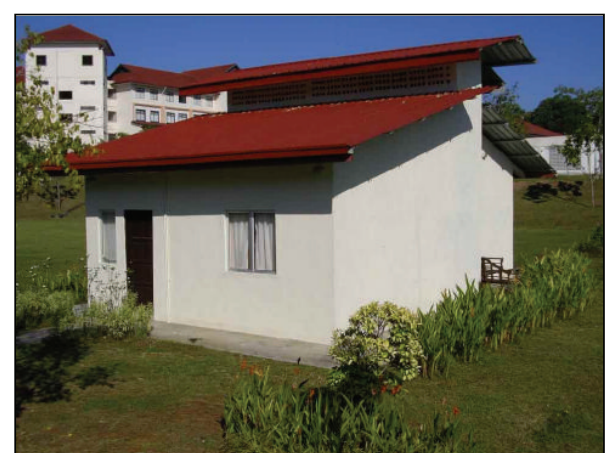

(b)

FIGURE 3: (a) Footbridge and (b) low cost house constructed using OPS concrete [16].

the reinforced POC beams was close to the prediction using BS 8110 design method, as only 1-7\% difference was observed. However, the experimental serviceability deflection values were about $10-45 \%$ lower compared to BS 8110. Despite this, the authors felt that the serviceability deflection for the singly reinforced POC beams was acceptable since it adhered to the limit stated in BS 8110. In the case of the doubly reinforced POC beams, similar to the finding by Teo et al. [5], it was recommended that larger beam depths should be used to ensure that the span-deflection ratio limit is satisfied. Apart from that, it was found that ACI 318 and BS 8110 gave reasonable crack width prediction at service loads for the reinforced POC beams. In addition, the crack widths at service loads obtained from the study were below the maximum permissible limit stipulated in ACI 318 and BS 8110. Based on the research carried out by Mohammed et al. [11], it could be summarized that the use of POC in reinforced concrete beam was suitable for structural application since most of the behaviour conformed to design codes and also comparable to other types of reinforced LWC beams which were done previously. In a separate study, Hussein et al. [20] carried out modelling works on reinforced POC beams with web openings using response surface methodology (RSM). The authors revealed that the use of RSM was capable of predicting the ultimate load of reinforced POC beams with web openings with an accuracy of $99.27 \%$.

Mohammed et al. [12] also carried out research on the shear behaviour of reinforced POC beams with varying tension reinforcement ratios, shear span to effective depth ratio, and compressive strength of POC. In general, the shear failure cracking observed for the reinforced POC beams was similar to that of conventional reinforced NWC beams. The increase in tension reinforcement ratio and compressive strength led to the increase in the shear strength of the reinforced POC beams while the effect of shear span to effective depth ratio on the reinforced POC beams was similar to that for conventional reinforced NWC beams. It is noteworthy that the shear strength prediction based on BS 8110, ACI, and EC2 overestimated the shear capacity of the reinforced POC beams and safety precaution should be taken to avoid underdesign of the shear capacity for reinforced POC beam. Nevertheless, it was suggested that
CSA based design could be used to predict the shear capacity for reinforced POC beam with tension reinforcement ratio exceeding $1 \%$ whereas a partial safety factor of 0.5 should be included when dealing with reinforced POC beam with tension reinforcement ratio of below $1 \%$. This study showed that reinforced POC beam exhibited similar shear failure as what would be expected of conventional reinforced concrete beam and this further justifies the usage of POC in reinforced concrete beam, bearing in mind that adequate safety factor should be applied when considering the ultimate shear capacity.

Comparison between the flexural behaviours of pretensioned prestressed POC and NWC beams was carried out by Omar and Mohamed [21]. In this investigation, the authors found that generally the failure mode of both POC and NWC beams was similar. It was also reported that only slight difference in load capacity and deflections of the beams was observed while the cracking behaviour was similar for both beams. Based on the findings from this work, it could be said that the performance of the prestressed POC beams is comparable to that of conventional prestressed NWC beam and does not cause significant structural deficiency.

2.2.2. Reinforced Concrete Slab. Mohammed et al. [22] used POC to fabricate composite floor slab with profiled steel sheeting and compared its flexural performance with the corresponding conventional NWC slab with both long and short shear spans. In the study, it was found that both types of slab failed in a similar manner, which was shear-bond failure. Nevertheless, all the slabs were considered to exhibit ductile behaviour. The deflection of the POC slab was found to be higher compared to conventional NWC slab and the authors reasoned this to the lower modulus of elasticity of POC. Despite this, the authors concluded that the behaviour of the POC slab was satisfactory and could be used for the construction of composite slabs. Since one of the main advantages of using composite deck slab is being a lightweight structure building material, the use of POC for such purpose could further enhance its application since the POC slab was found to have about $18 \%$ lower self-weight compared to NWC slab in this study. 


\subsection{Coconut Shell}

2.3.1. Reinforced Concrete Beam. The study on the reinforced CS concrete beam was initiated by Gunasekaran et al. [2]. In this investigation, singly and doubly reinforced CS concrete beams were tested under static flexural loading. It was observed that the failure mode of singly reinforced beams (designed as underreinforced) was due to the yielding of reinforcement followed by the concrete crushing in the compression zone whereas, for the case of doubly reinforced beams (designed as overreinforced), crushing of concrete occurred before the yielding of tension reinforcement. These observations showed that reinforced CS beam behaved similarly to conventional reinforced NWC beam. The general behaviour of the reinforced CS beam was also found to be similar to reinforced concrete beam using other types of LWA. Based on the experimental ultimate moment obtained from the experimental study, the authors concluded that BS 8110 and IS 456 could be used to provide a conservative design method for the ultimate moment of reinforced CS concrete beam. Similar to the observation by Teo et al. [5] and Mohammed et al. [11], the beam depth for the case of doubly reinforced CS concrete beam should be increased to satisfy the span-deflection ratio limit specified in BS 8110 and IS 456. The author found good ductility behaviour of the reinforced CS concrete beam, which was consistent with the investigation involving OPS concrete [6] and suggested that the CS concrete could be used in structural members in seismic region. In terms of cracking behaviour, the serviceability crack widths for the reinforced CS concrete beams were well below the maximum allowable limit stipulated in BS 8110 and IS 456 for durability purposes. In addition, the codes were able to provide reasonable prediction of the crack widths of the reinforced CS concrete beams.

Gunasekaran et al. [13] also investigated the shear behaviour of reinforced CS concrete beams. In this investigation, reinforced CS concrete and NWC beam with and without shear reinforcement were tested. The reinforced concrete beams without shear reinforcement, regardless of the type of concrete, exhibited shear failure whereas those with shear reinforcement showed flexural failure. Generally, the shear strength predicted using IS 456 was lower compared to the experimental value obtained for reinforced CS concrete beam and hence it could be said that IS 456 gives conservative shear strength design for reinforced CS concrete beam. When comparing the shear capacities of the reinforced coconut shell concrete and NWC beams, the authors found 4-8\% higher shear strength for the former when shear reinforcement was not provided and they attributed this to the aggregate interlock of CS. The shear capacity, as expected, increased about $20 \%$ and $50 \%$ when shear reinforcement was increased to $0.52 \%$ and $0.75 \%$, respectively. It was observed that the deflection of the reinforced CS concrete beams was higher compared to reinforced NWC beams both up to service load and at the ultimate load. Despite of this, the serviceability deflection of reinforced CS concrete beam was still within the allowable limit while higher ductility was also observed for the reinforced CS concrete beam due to its higher displacement-ductility ratio. In terms of the cracking behaviour, the reinforced CS beam generally showed better performance, with smaller crack width and crack spacing compared to conventional reinforced NWC beam. The authors reasoned this to the possible better bonding of reinforcement with CS concrete compared to NWC.

Another research was then carried out by Gunasekaran et al. [23] on the reinforced concrete CS concrete beam subjected to torsional load. The precracking behaviour of the reinforced CS concrete beam was found to be similar to that for the reinforced NWC beam. Even though the cracking of the reinforced CS concrete beams commenced earlier compared to the reinforced NWC beams, the use of both ACI method and MacGregor equation gave conservative prediction of the cracking torque strength for both types of reinforced concrete beams. Similarly, the ACI method and MacGregor equation also gave conservative prediction with regard to the ultimate torque strength. Nevertheless, it was found that the ultimate torque strength of the reinforced CS concrete beam was more than that of reinforced NWC beam and the authors attributed this to the presence of long and discrete fibres in the structure of the CS itself. Such reasoning was also said to contribute to the enhanced ductility of the reinforced CS concrete beam under torsional loading whereby the ductility was based on the maximum angle of twist. In the case of the determination of maximum angle of twist, the ACI method was found to be more suitable since it gave conservative prediction as compared to the MacGregor method which underestimated the maximum angle of twist. In terms of cracking behaviour, the crack width at the ultimate stage was generally slightly bigger for the reinforced CS concrete beam compared to the reinforced NWC beam. Generally, the research works carried out on reinforced CS concrete beams under flexural, shear, and torsional loading showed that CS concrete behaved similarly to conventional NWC in reinforced concrete beams and thus is feasible for actual structural applications.

\section{Acceptable Mix Design for Structural Use}

Table 1 summarizes all the mix designs used for the investigation of OPS, POC, and CS concrete in reinforced concrete members carried out in past researches. This could be used as a guide for future investigations or actual applications since the resulting reinforced concrete members were found to perform adequately as described earlier in Section 2. It should be noted that one common trait of the mix designs of the LWC was the high cement content and low amount of coarse aggregates and water used; this was such that sufficient strength could be attained for structural purposes.

\section{Recommendations}

The investigation on the use of agriculture waste materials as LWA in LWC for structural concrete members is still fairly new and research works have only begun less than a decade ago. In order to be fully convinced of the use of such materials, further works need to be carried out to 
TABLE 1: Mix design for LWC in reinforced concrete member.

\begin{tabular}{|c|c|c|}
\hline Mix design & $\begin{array}{c}\text { Mix proportion } \\
\text { Cement : sand : LWA : water }\end{array}$ & Remarks \\
\hline \multicolumn{3}{|l|}{ OPS concrete } \\
\hline $\begin{array}{l}\text { Teo et al. [5] } \\
\text { Teo et al. [16] } \\
\text { Teo et al. [17] }\end{array}$ & $1: 1.66: 0.60: 0.38$ & Cement content fixed at $510 \mathrm{~kg} / \mathrm{m}^{3}$ \\
\hline Alengaram et al. [6] & $1: 1.20: 0.80: 0.40$ & $\begin{array}{l}\text { Cement content fixed at } 480 \mathrm{~kg} / \mathrm{m}^{3} \\
5 \% \text { fly ash added } \\
10 \% \text { silica fume added } \\
1.0 \% \text { superplasticizer added }\end{array}$ \\
\hline Alengaram et al. [10] & $1: 1.20: 0.80: 0.40$ & $\begin{array}{l}\text { Cement content fixed at } 500 \mathrm{~kg} / \mathrm{m}^{3} \\
5 \% \text { fly ash added } \\
10 \% \text { silica fume added } \\
1.0 \% \text { superplasticizer added }\end{array}$ \\
\hline Jumaat et al. [9] & $1: 1.20: 0.80: 0.40$ & $\begin{array}{l}\text { Cement content fixed at } 420 \mathrm{~kg} / \mathrm{m}^{3} \\
6.7 \mathrm{~kg} / \mathrm{m}^{3} \text { foam content used } \\
5 \% \text { fly ash added } \\
10 \% \text { silica fume added } \\
0.5 \% \text { superplasticizer added }\end{array}$ \\
\hline Ahmed and Sobuz [7] & $\begin{array}{l}1: 1.71: 0.39: 0.41 \\
1: 1.65: 0.25: 0.45 \\
1: 1.65: 0.37: 0.45\end{array}$ & $\begin{array}{l}50 \% \text { OPS }+50 \% \text { granite } \\
10 \% \text { OPS }+90 \% \text { granite } \\
15 \% \text { OPS }+85 \% \text { granite }\end{array}$ \\
\hline Muda et al. [8] & $1: 1.5: 0.45: 0.40$ & $\begin{array}{l}5 \% \text { silica fume added } \\
2.0 \% \text { superplasticizer added }\end{array}$ \\
\hline \multicolumn{3}{|l|}{ POC concrete } \\
\hline Omar and Mohamed [21] & $1: 0.95: 1.26: 0.40$ & Cement content fixed at $512 \mathrm{~kg} / \mathrm{m}^{3}$ \\
\hline $\begin{array}{l}\text { Mohammed et al. [22] } \\
\text { Hussein et al. [20] }\end{array}$ & $1: 1.48: 0.69: 0.44$ & Cement content fixed at $500 \mathrm{~kg} / \mathrm{m}^{3}$ \\
\hline Mohammed et al. [12] & $\begin{array}{l}1: 0.95: 0.31: 0.20 \\
1: 0.95: 0.31: 0.40 \\
1: 0.95: 0.31: 0.60\end{array}$ & - \\
\hline \multicolumn{3}{|l|}{ CS concrete } \\
\hline $\begin{array}{l}\text { Gunasekaran et al. [2] } \\
\text { Gunasekaran et al. [13] } \\
\text { Gunasekaran et al. [23] }\end{array}$ & $1: 1.47: 0.65: 0.42$ & Cement content fixed at $510 \mathrm{~kg} / \mathrm{m}^{3}$ \\
\hline
\end{tabular}

combat the drawbacks on the use of such LWA in structural members as well as explore further applications with the use of such LWC. Based on the findings by Ahmed and Sobuz [7], it is recommended that the long term behaviour of such reinforced LWC members should be further researched since the higher creep and shrinkage as well as lower modulus of elasticity of LWC compared to NWC could result in poorer long term performance of the reinforced LWC members. Besides that, there is a need to carry out numerical simulations for such reinforced LWC members to further validate their structural performances. A good numerical model could also predict the performance of the reinforced concrete members accurately and hence significantly reduce the amount of experimental works required to test the specimens.

Findings obtained from the preliminary studies of LWC made with agriculture waste materials such as OPS could pave the way for future investigation of structural members. For instance, based on several studies involving the use of steel fibres in OPS concrete [24-26], the structural performance of such reinforced steel fibre concrete members under different kinds of loading, such as flexural and impact loading, could also be evaluated in the future.

Apart from that, based on previous research works for reinforced concrete members using other types of LWC, future investigations on the behaviour of the LWC with agriculture waste materials as LWA in reinforced concrete members could also be carried out. One of those includes investigation on reinforced concrete column subjected to axial force since Charif et al. [18] observed enhanced ductility of LWC columns compared to that for NWC columns. Furthermore, the increase in ductility was more significant compared to that for beam specimens. Tests on the reinforced LWC slabs under punching loads could also be carried out as demonstrated by Osman et al. [27] who reported higher ductility compared to conventional NWC. Punching test on reinforced LWC slabs containing lightweight shale, slate, and clay aggregates was also carried out by Youm et al. [28]. As reported by Kowalsky et al. [29], the performance of reinforced LWC columns made from lightweight expanded 
shale aggregates subjected to cyclic loading was satisfactory and this could encourage future works for LWC concrete made from agriculture waste materials. Another interesting research study could be the fabrication of structural wall panels using LWC. Cavaleri et al. [30] reported good performance of structural wall panels made from lightweight pumice concrete, subjected to constant vertical and cyclic horizontal loads. This could instigate the use of the aforementioned agriculture waste material such as OPS in LWC for structural wall panels since there is an additional advantage of improved thermal insulation of OPS concrete compared to conventional materials [31].

\section{Conclusions}

From this review, it was found that one of the main advantages with the use of LWC for reinforced concrete member is the enhanced ductility compared to conventional reinforced concrete member. This was observed for all types of agriculture waste materials such as OPS, POC, and CS concretes. Another interesting conclusion was the possible higher bond strength of the reinforcement with the LWC compared to NWC as observed by the smaller crack spacing and crack width of the reinforced concrete members. Most importantly, design codes such as BS and ACI were found to be suitable for the design and prediction of most of the reinforced LWC structural members subjected to flexural, shear, and torsional loadings. Nevertheless, further researches are essential in order to ascertain the structural feasibility of such reinforced LWC members with the ultimate aim of using these LWC members for actual structural applications in the future.

\section{Conflict of Interests}

The authors declare that there is no conflict of interests regarding the publication of this paper.

\section{Acknowledgment}

This research work was funded by the University of Malaya under the University of Malaya Research Grant (UMRG) RP018-2012B: Development of Geo-Polymer Concrete for Structural Application.

\section{References}

[1] M. A. Mannan and C. Ganapathy, "Concrete from an agricultural waste-oil palm shell (OPS)," Building and Environment, vol. 39, no. 4, pp. 441-448, 2004.

[2] K. Gunasekaran, R. Annadurai, and P. S. Kumar, "Study on reinforced lightweight coconut shell concrete beam behavior under flexure," Materials and Design, vol. 46, pp. 157-167, 2013.

[3] M. A. Mannan and C. Ganapathy, "Engineering properties of concrete with oil palm shell as coarse aggregate," Construction and Building Materials, vol. 16, no. 1, pp. 29-34, 2002.

[4] P. Shafigh, M. Z. Jumaat, and H. Mahmud, "Oil palm shell as a lightweight aggregate for production high strength lightweight concrete," Construction and Building Materials, vol. 25, no. 4, pp. 1848-1853, 2011.
[5] D. C. L. Teo, M. A. Mannan, and J. V. Kurian, "Flexural behaviour of reinforced lightweight concrete beams made with oil palm shell (OPS)," Journal of Advanced Concrete Technology, vol. 4, no. 3, pp. 459-468, 2006.

[6] U. J. Alengaram, M. Z. Jumaat, and H. Mahmud, "Ductility behaviour of reinforced palm kernel shell concrete beams," European Journal of Scientific Research, vol. 23, no. 3, pp. 406420, 2008.

[7] E. Ahmed and H. R. Sobuz, "Flexural and time-dependent performance of palm shell aggregate concrete beam," KSCE Journal of Civil Engineering, vol. 15, no. 5, pp. 859-865, 2011.

[8] Z. C. Muda, S. F. A. Sharif, and N. J. Hong, "Flexural behavior of lightweight oil palm shells concrete slab reinforced with geogrid," International Journal of Scientific \& Engineering Research, vol. 3, no. 11, 2012.

[9] M. Z. Jumaat, U. Johnson Alengaram, and H. Mahmud, "Shear strength of oil palm shell foamed concrete beams," Materials and Design, vol. 30, no. 6, pp. 2227-2236, 2009.

[10] U. J. Alengaram, M. Z. Jumaat, H. Mahmud, and M. M. Fayyadh, "Shear behaviour of reinforced palm kernel shell concrete beams," Construction and Building Materials, vol. 25, no. 6, pp. 2918-2927, 2011.

[11] B. S. Mohammed, W. L. Foo, and M. Abdullahi, "Flexural strength of palm oil clinker concrete beams," Materials and Design, vol. 53, pp. 325-331, 2014.

[12] B. S. Mohammed, W. L. Foo, K. M. A. Hossain, and M. Abdullahi, "Shear strength of palm oil clinker concrete beams," Materials \& Design, vol. 46, pp. 270-276, 2013.

[13] K. Gunasekaran, R. Annadurai, and P. S. Kumar, "Study on reinforced lightweight coconut shell concrete beam behavior under shear," Materials and Design, vol. 50, pp. 293-301, 2013.

[14] J. Kanadasan and H. A. Razak, "Mix design for self-compacting palm oil clinker concrete based on particle packing," Materials and Design, vol. 56, pp. 9-19, 2014.

[15] K. Gunasekaran, R. Annadurai, and P. S. Kumar, "Long term study on compressive and bond strength of coconut shell aggregate concrete," Construction and Building Materials, vol. 28, no. 1, pp. 208-215, 2012.

[16] D. C. L. Teo, M. A. Mannan, and V. J. Kurian, "Structural concrete using oil palm shell (OPS) as lightweight aggregate," Turkish Journal of Engineering and Environmental Sciences, vol. 30, no. 4, pp. 251-257, 2006.

[17] D. C. L. Teo, M. A. Mannan, and V. J. Kurian, "Structural behaviour of singly reinforced OPS beams," in Proceedings of the 6th Asia-Pacific Structural Engineering and Construction Conference (APSEC '06), Kuala Lumpur, Malaysia, 2006.

[18] A. Charif, M. J. Shannag, and S. Dghaither, "Ductility of reinforced lightweight concrete beams and columns," Latin American Journal of Solids and Structures, vol. 11, no. 7, pp. 12511274, 2014.

[19] S. H. Ahmad, Y. Xie, and T. Yu, "Shear ductility of reinforced lightweight concrete beams of normal strength and high strength concrete," Cement and Concrete Composites, vol. 17, no. 2, pp. 147-159, 1995.

[20] S. H. Hussein, K. M. B. Mustapha, Z. C. Muda, and S. Budde, "Modelling of ultimate load for lightweight palm oil clinker reinforced concrete beams with web openings using response surface methodology," International Journal of Civil Engineering and Technology, vol. 3, no. 1, pp. 33-44, 2012.

[21] W. Omar and R. N. Mohamed, "The performance of pretensioned prestressed concrete beams made with lightweight 
concrete," UTM Journal of Civil Engineering, vol. 14, no. 1, pp. 60-70, 2002.

[22] B. S. Mohammed, M. A. Al-Ganad, and M. Abdullahi, "Analytical and experimental studies on composite slabs utilising palm oil clinker concrete," Construction and Building Materials, vol. 25, no. 8, pp. 3550-3560, 2011.

[23] K. Gunasekaran, R. Ramasubramani, R. Annadurai, and S. Prakash Chandar, "Study on reinforced lightweight coconut shell concrete beam behavior under torsion," Materials and Design, vol. 57, pp. 374-382, 2014.

[24] S. P. Yap, C. H. Bu, U. J. Alengaram, K. H. Mo, and M. Z. Jumaat, "Flexural toughness characteristics of steelpolypropylene hybrid fibre-reinforced oil palm shell concrete," Materials and Design, vol. 57, pp. 652-659, 2014.

[25] K. H. Mo, K. K. Q. Yap, U. J. Alengaram, and M. Z. Jumaat, "The effect of steel fibres on the enhancement of flexural and compressive toughness and fracture characteristics of oil palm shell concrete," Construction and Building Materials, vol. 55, pp. 20-28, 2014.

[26] K. H. Mo, S. P. Yap, U. J. Alengaram, M. Z. Jumaat, and C. H. $\mathrm{Bu}$, "Impact resistance of hybrid fibre-reinforced oil palm shell concrete," Construction and Building Materials, vol. 50, pp. 499507, 2014.

[27] M. Osman, H. Marzouk, and S. Helmy, "Behavior of highstrength lightweight concrete slabs under punching loads," ACI Structural Journal, vol. 97, no. 3, pp. 492-498, 2000.

[28] K.-S. Youm, J. J. Kim, and J. Moon, "Punching shear failure of slab with lightweight aggregate concrete (LWAC) and low reinforcement ratio," Construction and Building Materials, vol. 65, pp. 92-102, 2014.

[29] M. J. Kowalsky, M. J. N. Priestley, and F. Seible, "Shear and flexural behavior of lightweight concrete bridge columns in seismic regions," ACI Structural Journal, vol. 96, no. 1, pp. 136148, 1999.

[30] L. Cavaleri, N. Miraglia, and M. Papia, "Pumice concrete for structural wall panels," Engineering Structures, vol. 25, no. 1, pp. 115-125, 2003.

[31] U. Johnson Alengaram, B. A. Al Muhit, M. Z. bin Jumaat, and M. L. Y. Jing, "A comparison of the thermal conductivity of oil palm shell foamed concrete with conventional materials," Materials and Design, vol. 51, pp. 522-529, 2013. 

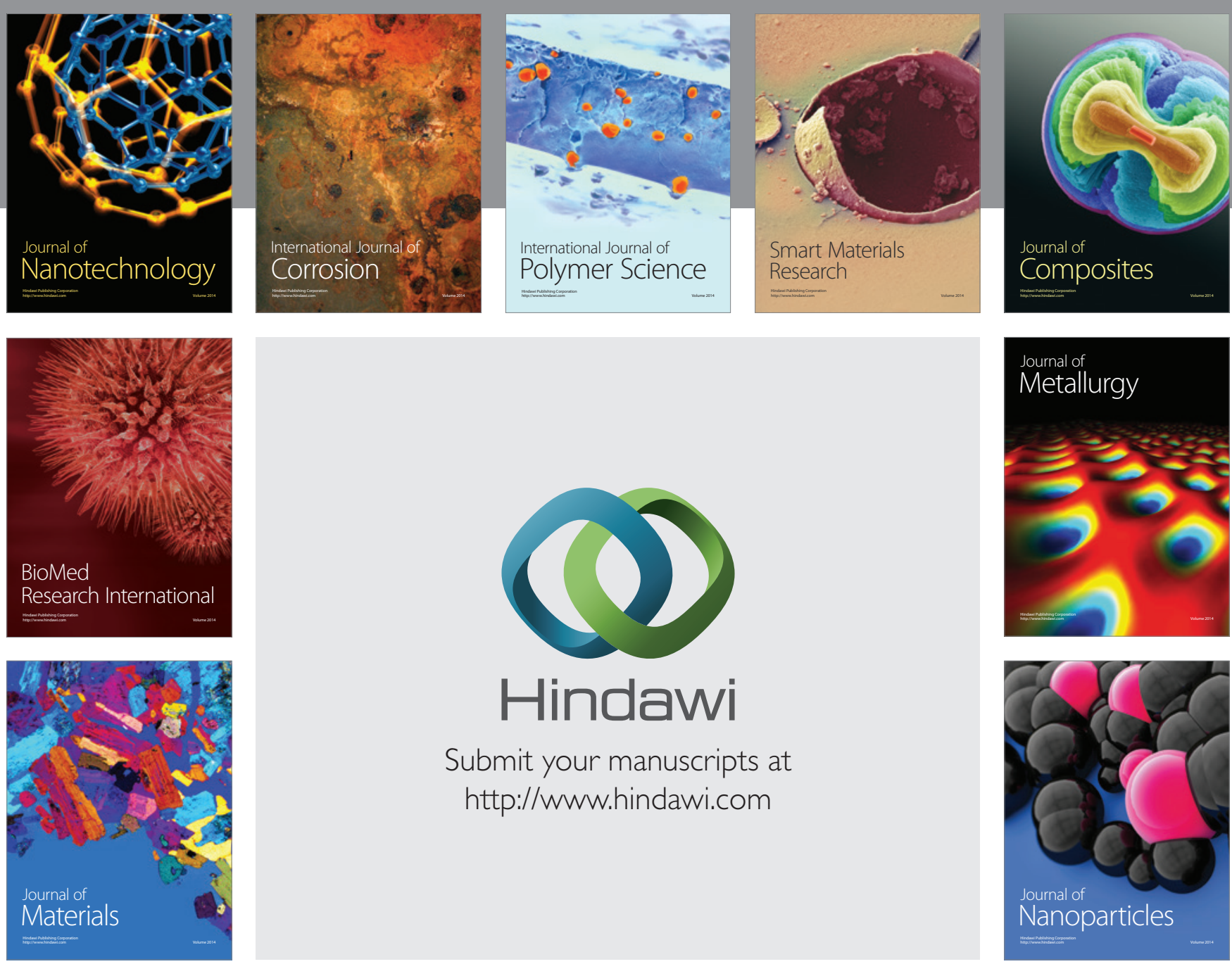

Submit your manuscripts at http://www.hindawi.com
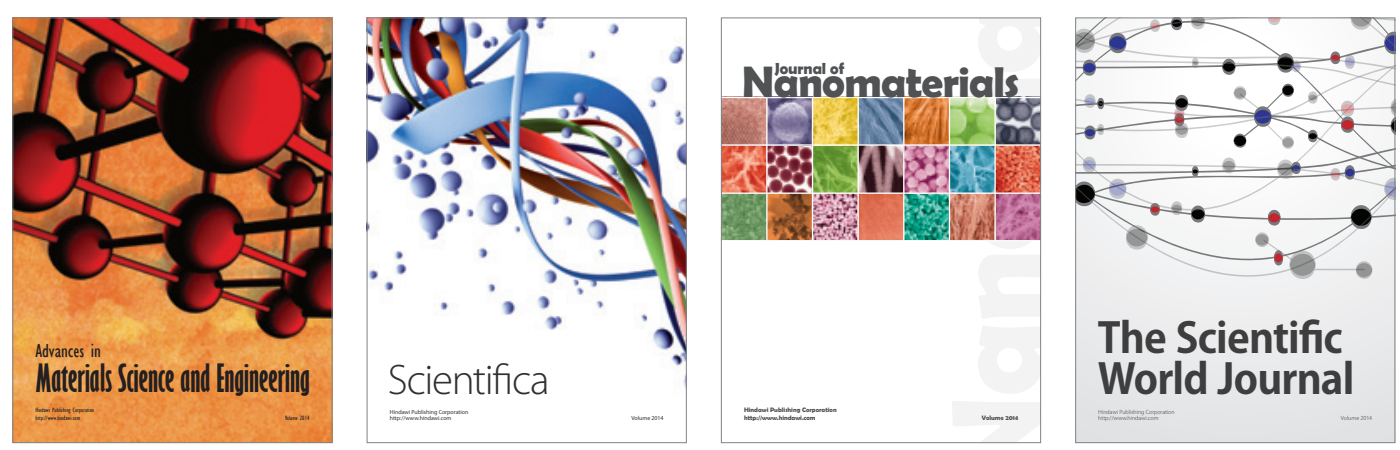

\section{The Scientific World Journal}
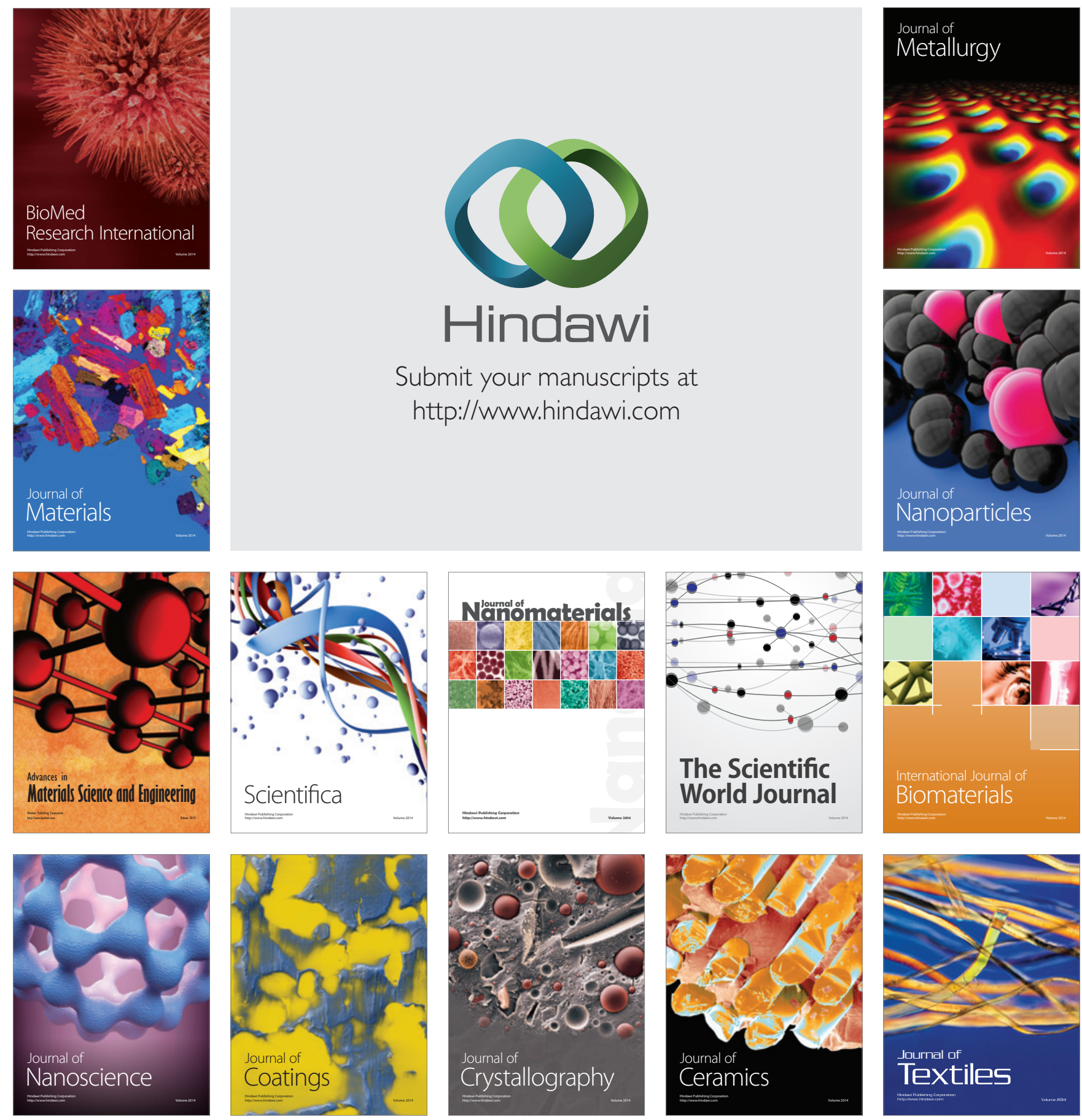